\title{
Biofilm Formation of Staphylococcus aureus Isolated from Infected Wound
}

\author{
Alaa El Din Hassan Mohammed, Mona Fattouh Mohamed, Asmaa \\ Mohamed Goda,Samah Raafat Mohamed. \\ General Surgery Department, Faculty of Medicine, Sohag University, Sohag, \\ Egypt \\ Microbiology Department, Faculty of Medicine, Sohag University, Sohag, Egypt
}

\begin{abstract}
Background: Staphylococcus aureus has the ability to form biofilms, and causes significant mortality and morbidity in the patients with wounds. Our aim was to study the in vitro biofilm-forming ability of isolated $S$. aureus

patients and methods: one hundred clinical isolates of $S$. aureus were isolated from 350 pus samples using standard microbiological techniques. Biofilm formation ability of these isolates was detected phenotypically by tissue culture plate (TCP) method and congo red agar (CRA) and genotypically by detection of ica ABCD genes by PCR.

Results: The clinical isolates of $S$. aureus recovered from infected wounds exhibit a high degree of biofilm formation Biofilm formation was observed in (76 \%), (74\%) and $(70 \%)$ isolates of $S$. aureus via TCP method CRA and genotypically, respectively.

Conclusion: This study illustrated that PCR method can be adopted as most suitable an reproducible method for detection of biofilm. CRA is qualitative, simple, inexpensive and easily reproducible method and convenient as screening method. TCP is semiquantitative method and remains a precious tool for in vitro screening of different biomaterial for the adhesive properties. Regular surveillance of biofilm formation by $S$. aureus leads to the early treatment of the wound infection.
\end{abstract}

biofilm encased in EPS. In fact, biofilm formation involves the production of polysaccharide intercellular adhesin, which depends on the expression of the intercellular adhesion (IcaADBC) operon that encodes three membrane proteins (IcaA, IcaD and IcaC) and one extracellular protein (IcaB) [2].

Biofilm formation by $S$. aureus can lead to a delay in reepithelialization of the infected tissues, ultimately increasing healing time. $S$. aureus biofilms have been associated with chronic wounds like diabetic foot ulcer, pressure sores and venous ulcers. Detachment of matured biofilm of $S$. aureus is a prerequisite for the dissemination of wound infection [3].

\section{Introduction}

Staphylococcus aureus is an opportunistic pathogen implicated as the most common agent of skin and soft tissue infections. It can breach the skin barriers through the wound or surgical incision and cause infection. Furthermore, it has the ability to adhere to and form a biofilm on tissues or medical indwelling devices [1]. Biofilms are the aggregation of bacteria embedded in a self-produced extracellular matrix of exopolysaccharides (EPSs), proteins and some micromolecules such as DNA. They can form on both biotic and abiotic surfaces [2]. $S$. aureus initially adheres to a solid substrate, after which cell-cell adhesion occurs; the bacteria then multiply to form a multilayered 
- Assay of biofilm production by $S$. aureus using Congo Red Agar (CRA): The isolates were cultured on CRA plates, prepared by adding $0.8 \mathrm{~g}$ of Congo red stain (Oxoid, UK) and $36 \mathrm{~g}$ of sucrose to $1 \mathrm{~L}$ of $\mathrm{BHI}$ (both from Oxoid, UK). After $24 \mathrm{~h}$ incubation at $37^{\circ} \mathrm{C}$, isolates with red colonies were considered to be non-slime producing, and those with black colonies were considered to be slime- producing or biofilm-producers [5].

- Assay of biofilm production by $S$. aureus using microtiter plate assay (MtP) [6]. Isolates from fresh agar plates were inoculated in trypticase soy broth with $1 \%$ glucose and incubated for 24 hours at $37^{\circ} \mathrm{C}$ in stationary condition and diluted ( 1 in $100)$ with fresh medium. Individual wells of sterile, polystyrene, flatbottom tissue culture plates were filled with $0.2 \mathrm{ml}$ aliquots of the diluted cultures, and only broth served as control to check sterility and nonspecific binding of media. The tissue culture plates were incubated for 24 hours at $37^{\circ} \mathrm{C}$. After incubation, the content of each well was gently removed by tapping the plates. The wells were washed four times with 0.2 $\mathrm{ml}$ of phosphate buffer saline (PBS $\mathrm{pH}$ 7.2) to remove free floating planktonic bacteria. Biofilm formed by bacteria adherent to the wells were fixed by $2 \%$ sodium acetate for 20 minutes and stained by crystal violet $(0.1 \%)$. The plates were incubated at room temperature for 15 minutes, rinsed thoroughly and repeatedly with water. Crystal violet-stained biofilm was solubilized in $200 \mu \mathrm{L}$ of $95 \%$ ethanol (to extract the violet color), of which $125 \mu \mathrm{L}$ were transferred to a new polystyrene microtiter dish, which was then read. Optical density (OD) of stained adherent bacteria was determined with ELISA autoreader (Stat Fax 2100 autoreader) at wave length of $545 \mathrm{~nm}$. Experiments for
Biofilms can resist antibiotic concentration 10-10,000 folds higher than those required to inhibit the growth of free floating bacteria [4].So, regular surveillance of biofilm formation by $S$. aureus and their antimicrobial resistance profile may lead to the early treatment of the wound infection. Therefore, our aim was to study the in vitro biofilmforming ability of $S$. aureus isolated from wounds of hospitalized patients .

\section{Patients and Methods}

This study was conducted in Department of Medical Microbiology and Immunology, Faculty of Medicine, Sohag University. Pus from infected wounds were collected by sterile disposable cotton swabs. Samples were collected from patients admitted at Sohag University Hospitals from different surgical departments. All Staphylococcus aureus isolates were identified by, Gram staining (Gram positive cocci in grape like clusters) colony morphology (golden on nutrient agar ,beta hemolytic on blood agar and caused yellow discoloration on mannitol salt agar) and conventional biochemical tests (positive catalase and coagulase tests).

The following data were collected from patients:

1) Patients demographic data.

2) Possible risk factors as implants ,DM , use of broad-spectrum antimicrobials ,previous hospital admission and chronic diseases (other than DM) that affect wound healing like anemia, ischemia, renal and liver diseases

Phenotypic Detection of Biofilm Formation: Two phenotypic methods were used for detecting the biofilm production of the staphylococcal isolates; one qualitative (Congo red agar method) and another quantitative (Microtiter plate method). 
SOHAG MEDICALJOURNAL Vol. 22 No.3 October 2018 ii. DNA amplification :The amplification reactions were prepared in a $25 \mu \mathrm{l}$ volume containing the following; 12.5 $\mu 1$ PCR master mix (Gene Direx), $7 \mu \mathrm{l}$ Sterile Water,1.25 $\mu \mathrm{l}$ forward primer , $1.25 \mu \mathrm{l}$ reverse primer and $3 \mu \mathrm{l}$ DNA. Each of the oligonucleotide primers specific for icaA ,ica B , ica C and icaD, respectively (see table 1 for the sequences) .The thermal amplification program for ica A and ica D included the following steps: an initial denaturation at $95^{\circ} \mathrm{C}$ for $5 \mathrm{~min}$; 50 cycles of amplification with $94^{\circ} \mathrm{C}$ for $30 \mathrm{~s}$ (denaturation), $55.5^{\circ} \mathrm{C}$ for $30 \mathrm{~s}$ (annealing), $\quad 72^{\circ} \mathrm{C}$ for $1 \mathrm{~min}$ extension); and then final extension at $72^{\circ} \mathrm{C}$ for $2 \mathrm{~min}$. The thermal amplification program for ica $\mathrm{B}$ and ica $\mathrm{C}$ included the following steps: an initial denaturation at $95^{\circ} \mathrm{C}$ for $5 \mathrm{~min}$; 30 cycles of amplification with $94^{\circ} \mathrm{C}$ for $1 \mathrm{~min}$ (denaturation), $59^{\circ} \mathrm{C}$ ( ica $\mathrm{B}$ ) and $45{ }^{\circ} \mathrm{C}$ (ica $\mathrm{C}$ ) for $1 \mathrm{~min}$ (annealing), $72^{\circ} \mathrm{C}$ for 2.5 min extension); and then final extension at $72^{\circ} \mathrm{C}$ for $10 \mathrm{~min}$.

iii. Detection of the amplified genes: 10 $\mu l$ of the amplification products were electrophoresed on agarose gel along with molecular weight marker100 bp DNA ladder, and the presence or absence of any resulting bands was evaluated under ultraviolet transillumination. each strain were performed in triplicate and repeated three times. To compensate for background absorbance, OD readings from sterile medium were averaged and subtracted from all test results., and average OD values of negative controls and samples were calculated separately. Optical density cut-off value $(\mathrm{ODc})=$ average OD of negative control +3 standard deviation (SD) of negative control [6].

Interpretation of results was described as follows:[7]

1. $\mathrm{OD} \leq \mathrm{ODc}=$ Non biofilm producer $(\mathrm{N})$.

2. ODc $<\mathrm{OD} \leq 2 \mathrm{ODc}=$ Weak biofilm producer (WP).

3. $2 \mathrm{ODc}<\mathrm{OD} \leq 4 \mathrm{ODc}=$ Moderate biofilm producer (MP).

4. 4ODc < $\mathrm{OD}=$ Strong biofilm producer(SP).

Genotypic detection of BiofilmFormation

Simple qualitative polymerase chain reaction for detection of ica $\mathrm{ABCD}$ genes was done as follows:

i. DNA extraction (the boiling method):Few isolated colonies of overnight growth bacteria were suspended thoroughly in $50 \mu \mathrm{l}$ sterile distilled water. The suspension was boiled in a water bath, for $10 \mathrm{~min}$. It was centrifuged at $10000 \mathrm{rpm}$ for 5 min, The supernatant was taken as a template and stored at $-20^{\circ} \mathrm{C}[8]$.

Table (1): primers used in the study

\begin{tabular}{|l|l|l|l|c|}
\hline Gene & \multicolumn{1}{|c|}{ Primer } & \multicolumn{1}{|c|}{ Nucleotide Sequence } & Amplicon size & $\begin{array}{c}\text { Refer } \\
\text { ence }\end{array}$ \\
\hline Ica A & $\begin{array}{l}\text { Forward } \\
\text { Reverse }\end{array}$ & $\begin{array}{l}\text { 5'-TCTCTTGCAGGAGCAATCAA -3' } \\
\text { 5'-TCAGGCACTAACATCCAGCA -3 }\end{array}$ & $\mathbf{1 8 8}$ bp & {$[9]$} \\
\hline Ica B & $\begin{array}{l}\text { Forward } \\
\text { Reverse }\end{array}$ & $\begin{array}{l}\text { 5'-ATG GCT TAA AGC ACA CGA CGC -3' } \\
\text { 5'- TAT CGG CAT CTG GTG TGA CAG -3 }\end{array}$ & $\mathbf{5 2 6}$ bp & {$[10]$} \\
\hline Ica C & $\begin{array}{l}\text { Forward } \\
\text { Reverse }\end{array}$ & $\begin{array}{l}\text { 5' TGCATTTTATCGATCAGGGC 3' } \\
\text { 5' CACTTCCTTTTCCAGGACG 3' }\end{array}$ & $\mathbf{9 8 9}$ bp & {$[10]$} \\
\hline Ica D & $\begin{array}{l}\text { Forward } \\
\text { Reverse }\end{array}$ & $\begin{array}{l}\text { 5'-ATA AAC TTG AAT TAG TGT ATT -3' } \\
\text { 5'-ATA TAT AAA ACT CTC TTA ACA -3 }\end{array}$ & $\mathbf{1 9 8}$ bp & {$[9]$} \\
\hline
\end{tabular}

\section{Results}

The study included 350 patients with wound infections isolated from patients recruited from different departments. Staphylococcus aureus was isolated in 100 patients .

i. Detection of Biofilm formation by phenotypic methods: 
SOHAG MEDICALJOURNAL

Vol. 22 No.3 October 2018
Biofilm Formation of Staphylococcus aureus Isolated from Infected

Samah Raafat Mohamed

- Biofilm formation by tissue culture plate method; $24 \%$ of S.aureus isolates were non biofilm producers and $76 \%$ were positive biofilm producers (9\%weak,48\%modeate and $19 \%$ strong)

- Biofilm formation by congo red method; $26 \%$ of S.aureus isolates were non biofilm producers and $74 \%$ were positive biofilm producers (29\%modeate and $45 \%$ strong). Congo red has statistically significant correlation with TCP $(\boldsymbol{p}$ value $=\mathbf{0 . 0 0 1})($ Table 2$)$.

Table(2): Distribution of the studied patients according to the results of Congo red and TCP test

\begin{tabular}{|l|l|l|l|l|l|}
\hline \multirow{2}{*}{$\begin{array}{l}\text { Congo red } \\
\text { test }\end{array}$} & \multicolumn{2}{|l|}{ TCP test } & \multirow{2}{*}{$\begin{array}{l}\text { P- } \\
\text { value }\end{array}$} \\
\cline { 2 - 5 } & $\begin{array}{l}\text { Non } \\
\text { NO. }(\%)\end{array}$ & $\begin{array}{l}\text { Weak } \\
\text { NO. }(\%)\end{array}$ & $\begin{array}{l}\text { Moderate } \\
\text { NO. }(\%)\end{array}$ & $\begin{array}{l}\text { Strong } \\
\text { NO. }(\%)\end{array}$ & \\
\hline Non /Weak & $\mathbf{1 2}(46.2 \%)$ & $\mathbf{3 ( 1 1 . 5 \% )}$ & $\mathbf{9 ( 3 4 . 6 \% )}$ & $\mathbf{2}(7.7 \%)$ & \multirow{2}{*}{.001* } \\
\hline Moderate & $\mathbf{3 ( 1 0 . 3 \% )}$ & $\mathbf{4 ( 1 3 . 8 \% )}$ & $\mathbf{2 0}(69.0 \%)$ & $\mathbf{2 ( 6 . 9 \% )}$ & \\
\hline Strong & $\mathbf{9 ( 2 0 . 0 \% )}$ & $\mathbf{2 ( 4 . 4 \% )}$ & $\mathbf{1 9}(42.2 \%)$ & $\mathbf{1 5}(33.3 \%)$ & \\
\hline
\end{tabular}

ii. Detection of Biofilm formation by genotypic method (PCR ; detection of ica genes)

- Regarding presence of one or more of ica genes in S.aureus strains; $70 \%$ positive and $30 \%$ negative

- We found that there Ica A was present in $23 \%$ of isolates, Ica B was present in $11 \%$ of isolates, Ica $\mathrm{C}$ was present in $9 \%$ of isolates and Ica D was present in $70 \%$ of isolates.

iii. comparison between TCP, congo and genotypic method for detection of biofilm formation

- On comparison between TCP and genotypic method for detection of biofilm formation; sensitivity of TCP in comparison to PCR was $97.1 \%$, specificity was $73.3 \%$, positive predictive value was $89.5 \%$ and negative predictive value was $91.7 \%$. Two isolate was positive biofilm producer by PCR and negative biofilm producer by TCP. Eight isolates were non biofilm producers by PCR and positive biofilm producers by TCP method. There was high statistically significant relation between TCP and PCR mehods for detection of biofilm (p value $\mathbf{0 . 0 0 0 1}$ ) (table 2,3).

- On comparison between congo red and genotypic method for detection of biofilm formation ;sensitivity of congo red method in comparison with PCR was 77.1\%, specificity was $33.3 \%$, positive predictive value was $73 \%$ and negative predictive value was $38.5 \%$. Sixteen isolates was positive biofilm producer by PCR and negative biofilm producer by congo red method. Twenty isolates were non biofilm producers by PCR and positive biofilm producers by congo red method. There was statistically significant relation between CRA and PCR methods for detection of biofilm ( $\boldsymbol{p}$ value $\mathbf{= 0 . 0 0 8}$ ) (table $3,4)$

Table (3): Comparison between the results of Congo red and TCP test and PCR.

\begin{tabular}{|c|c|c|c|c|c|}
\hline \multirow{3}{*}{ TCP } & \multicolumn{4}{|c|}{ Biofilm formation genotypiclly } & \multirow[t]{2}{*}{ P-value } \\
\hline & \multicolumn{2}{|c|}{$\begin{array}{l}\text { No (-ve) } \\
\text { N.=30(30.0\%) }\end{array}$} & \multicolumn{2}{|c|}{$\begin{array}{l}\text { Yes (+ve) } \\
\text { N.=70(70.0\%) }\end{array}$} & \\
\hline & & & & & \\
\hline No (-ve) & 22 & (73.3) & 2 & (2.9) & $<0.0001 *$ \\
\hline Yes (+ve) & 8 & (26.7) & 68 & (97.1) & \\
\hline Congo red & & & & & \\
\hline No (-ve) & 10 & (33.3) & 16 & (22.9) & $0.008 *$ \\
\hline Yes $(+v e)$ & 20 & (66.7) & 54 & $(77.1)$ & \\
\hline
\end{tabular}

Table (4): Sensitivity, specificity, positive predictive value (PPV), negative predicative value (NPV) of TCP and Congo red

\begin{tabular}{|l|l|l|l|l|}
\hline & $\begin{array}{l}\text { Sensitivit } \\
\mathbf{y}\end{array}$ & $\begin{array}{l}\text { Specificit } \\
\mathbf{y}\end{array}$ & PPV & NPV \\
\hline TCP & $\mathbf{9 7 . 1}$ & $\mathbf{7 3 . 3}$ & $\mathbf{8 9 . 5}$ & $\mathbf{9 1 . 7}$ \\
\hline Congo red & $\mathbf{7 7 . 1}$ & $\mathbf{3 3 . 3}$ & $\mathbf{7 3}$ & $\mathbf{3 8 . 5}$ \\
\hline
\end{tabular}


SOHAG MEDICALJOURNAL

Vol. 22 No.3 October 2018
Biofilm Formation of Staphylococcus aureus Isolated from Infected Samah Raafat Mohamed

iv. Some the possible risk factors for biofilm formation by S.aureus in infected wounds were studied and results shown in table 5. 
Table (5): comparison between biofilm forming and non biofilm forming groups regarding possible risk factors.

\begin{tabular}{|c|c|c|c|}
\hline & \multicolumn{2}{|c|}{ Biofilm formation } & \multirow[t]{2}{*}{ P-value } \\
\hline & $\begin{array}{l}\text { Yes } \\
\text { N.=70(70.0\%) }\end{array}$ & $\begin{array}{l}\text { No } \\
\text { N.=30(30.0\%) }\end{array}$ & \\
\hline $\begin{array}{c}\text { Age } \\
\text { Mean } \pm \text { S.D. } \\
\text { Median(Range) }\end{array}$ & $\begin{array}{c}35.1 \pm 21.6 \\
31.0(4.0-70.0)\end{array}$ & $\begin{array}{c}37.0 \pm 19.0 \\
40.0(4.0-72.0)\end{array}$ & 0.585 \\
\hline $\begin{array}{c}\text { Sex } \\
\text { Male }(\%) \\
\text { Female (\%) }\end{array}$ & $\begin{array}{l}41(83.7 \%) \\
29(56.9 \%)\end{array}$ & $\begin{array}{c}8(16.3 \%) \\
22(43.1 \%)\end{array}$ & 0.003* \\
\hline $\begin{array}{c}\text { Bed Sores } \\
\text { No }(\%) \\
\text { yes }(\%)\end{array}$ & $\begin{array}{c}63(67.7 \%) \\
7(100 \%) \\
\end{array}$ & $\begin{array}{c}30(32.3 \%) \\
0(0.0 \%)\end{array}$ & 0.001* \\
\hline $\begin{array}{c}\text { Burn } \\
\text { No }(\%) \\
\text { yes }(\%)\end{array}$ & $\begin{array}{l}68(75.6 \%) \\
2(20.0 \%)\end{array}$ & $\begin{array}{l}22(24.4 \%) \\
8(80.0 \%)\end{array}$ & 0.099 \\
\hline $\begin{array}{l}\text { Diabetic foot } \\
\text { No }(\%) \\
\text { yes }(\%) \\
\end{array}$ & $\begin{array}{c}55(67.1 \%) \\
15(83.3 \%)\end{array}$ & $\begin{array}{c}27(32.9 \%) \\
3(16.7 \%)\end{array}$ & 0.173 \\
\hline $\begin{array}{c}\text { Surgical Wound } \\
\text { No }(\%) \\
\text { yes }(\%)\end{array}$ & $\begin{array}{l}26(65.0 \%) \\
44(73.3 \%)\end{array}$ & $\begin{array}{l}14(35.0 \%) \\
16(26.7 \%)\end{array}$ & 0.373 \\
\hline $\begin{array}{c}\text { Traumatic Wound } \\
\text { No }(\%) \\
\text { yes }(\%)\end{array}$ & $\begin{array}{c}68(71.6 \%) \\
2(40.0 \%)\end{array}$ & $\begin{array}{c}27(28.4 \%) \\
3(60.0 \%)\end{array}$ & 0.158 \\
\hline $\begin{array}{c}\text { Diabetes Mellitus } \\
\text { No }(\%) \\
\text { yes }(\%) \\
\end{array}$ & $\begin{array}{l}51(68.0 \%) \\
19(76.0 \%) \\
\end{array}$ & $\begin{array}{c}24(32.0 \%) \\
6(24.0 \%) \\
\end{array}$ & 0.450 \\
\hline $\begin{array}{l}\text { Foreign body } \\
\text { No }(\%) \\
\text { yes }(\%)\end{array}$ & $\begin{array}{l}43(64.2 \%) \\
27(81.8 \%)\end{array}$ & $\begin{array}{c}24(35.8 \%) \\
6(18.2 \%)\end{array}$ & 0.070 \\
\hline $\begin{array}{c}\text { Previous hospital } \\
\text { admission } \\
\text { No }(\%) \\
\text { yes }(\%) \\
\end{array}$ & $\begin{array}{l}24(53.3 \%) \\
46(83.6 \%)\end{array}$ & $\begin{array}{c}21(46.7 \%) \\
9(16.4 \%)\end{array}$ & 0.001* \\
\hline $\begin{array}{c}\text { Use of broad spectrum } \\
\text { antibiotics } \\
\text { No }(\%) \\
\text { yes }(\%) \\
\end{array}$ & $\begin{array}{l}22(51.2 \%) \\
48(84.2 \%)\end{array}$ & $\begin{array}{c}21(48.8 \%) \\
9(15.8 \%)\end{array}$ & 0.001* \\
\hline $\begin{array}{l}\text { Steroid } \\
\text { No }(\%) \\
\text { yes }(\%\end{array}$ & $\begin{array}{c}64(91.4 \%) \\
6(8.6 \%)\end{array}$ & $\begin{array}{l}25(83.3 \%) \\
5 \quad(16.7 \%)\end{array}$ & 0.298 \\
\hline $\begin{array}{c}\text { Chronic disease } \\
\text { No }(\%) \\
\text { yes }(\%)\end{array}$ & $\begin{array}{l}23(32.9 \%) \\
47(67.1 \%)\end{array}$ & $\begin{array}{c}30(100 \%) \\
0(0.0 \%)\end{array}$ & $\begin{array}{c}<0.0001 \\
*\end{array}$ \\
\hline
\end{tabular}

$\boldsymbol{P}$ - value was calculated by Chi square test and Fisher's Exact Test * Statistically significant 


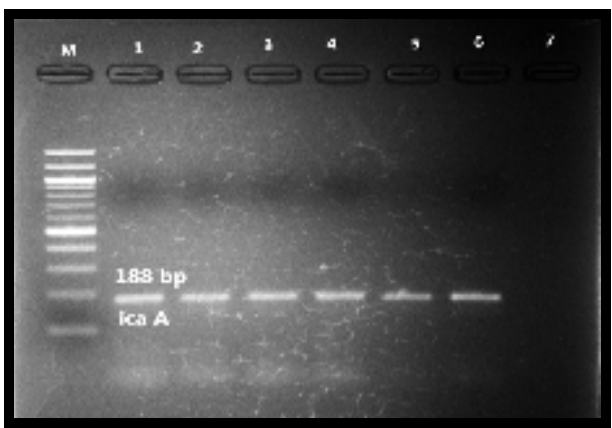

Figure (1): Electrophoresis of PCR products with primers for ica A. Lane M, $100 \mathrm{bp}$ molecular weight marker; from lane1,to lane 6, 188-bp bands from ica A positive samples; lane 7 , negative control.

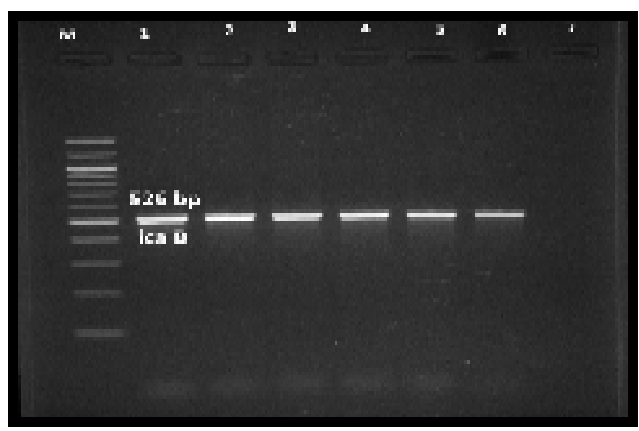

Figure (2): Electrophoresis of PCR products with primers for ica B. Lane M, $100 \mathrm{bp}$ molecular weight marker; from lane1,to lane 6,526 -bp bands from ica B positive samples; lane 7 , negative control

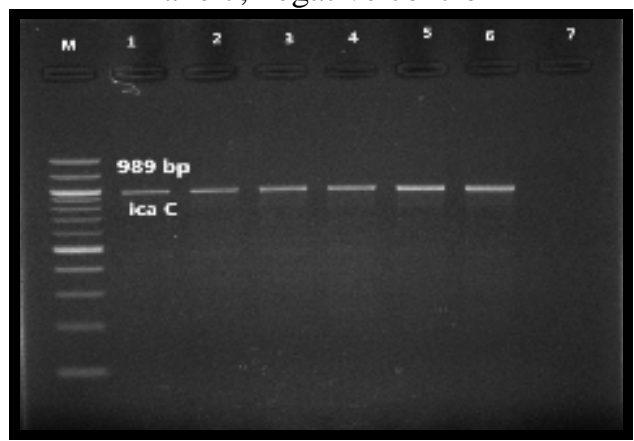

Figure (3): Electrophoresis of PCR products with primers for ica C. Lane M, $100 \mathrm{bp}$ molecular weight marker; from lane1,to lane 6,989 -bp bands from ica $\mathrm{C}$ positive samples;

lane 7 , negative control.

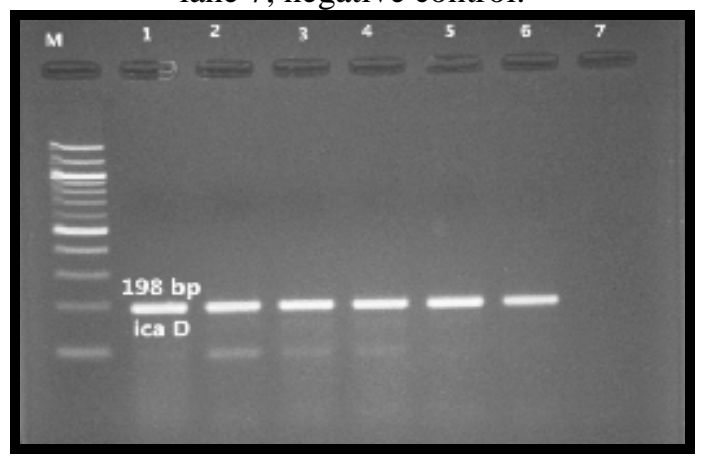

Figure (4): Electrophoresis of PCR products with primers for ica D. Lane M, $100 \mathrm{bp}$ molecular weight marker; from lane1,to lane 6, 198-bp bands from ica D positive samples; lane 7 , negative control 


\section{Discussion}

Biofilm formation by tissue culture plate method; $24 \%$ of S.aureus isolates were non biofilm producers and $76 \%$ were positive biofilm producers (19\% strong $48 \%$ modeate, and $9 \%$ weak). Other studies that investigated biofilm formation by S.aureus in wounds showed also high prevalence of biofilm formation Neopane et al.,(2018) [2] (69.8\%;6.97 strong $27.90 \%$ moderate and $34.88 \%$ weak) and Yazdani et al.(2006) [11] (52\%). In another study in Egypt, Gad et al. (2009)[12] reported higher prevalence of biofilm formation by S.aureus but in urine samples inpatients undergoing ureteral catheterization $(83.3 \%$; 66.7\% strong biofilm $16.7 \%$ moderate and $16.7 \%$ non or weak). A lower rate of biofilm formation was demonstrated by Nasr et al. (2012) [13] where $46 \%$ of S.aureus isolates produce biofilm by TCP assay ; 26\% strong producers, $12 \%$ moderate and $8 \%$ weak biofilm producers. Variation may be due to different type of samples, presence of foreign body, different growth conditions and the use of various sugar supplementations for biofilm formation in staphylococci.

Our data, using samples isolated from wound and pus, are in coordenence to that of a previous report that showed $66.67 \%$ biofilm formation in the blood samples (Poudel et al., 2015) [14] The potential for biofilm formation in wounds and pus may be similar to that in the blood. Biofilm formation depends on many factors such as environment, availability of nutrients, geographical origin, types of specimen, surface adhesion characteristics and genetic makeup of the organism[15]. These factors may have affected the data and contributed to the high prevalence observed in the present study. However, it is not known as to how these factors are involved. Biofilms can form on any wound when planktonic bacteria are not eliminated by the host's immune system or by exogenous antimicrobial agents. In addition, mutations in Ica and regulatory genes have been associated with reduced capacity of $S$. aureus to form biofilms[16].Taken together, these factors may have affected the results in the present study.

Biofilm formation by congo red method; $26 \%$ of S.aureus isolates were non biofilm producers and $74 \%$ were positive biofilm producers $(29 \%$ modeate and 45\%strong). Namvar (2013) [17]. and Nasr et al., ( 2012) [13]. also reported $65 \%$ positive results with congo red agar. However Taj et al.(2012) [18]. reported that only four isolates (3.4\%) were positive by CRA test .

Congo red had statistically significant correlation with TCP ( $\boldsymbol{p}$ value =0.001). Our findings are contradictory with Nasr et al.(2012) [13] who reported that CRA method showed little correlation with MTP assay where only (20\%) of the isolates were positive by both the MTP and CRA methods. A low correspondence between both methods was also demonstrated by 
Marthur et al.(2006) [19].On the other hand, better correlation between both methods were reported by other investigators where all staphylococci positive by one test were also positive by the other (Cafiso et al. 2004) [20].Environmental factors like sugars (glucose or lactose) or proteases present in the growth medium, surface area, type of surface (rough/smooth), porosity, charge of the surface and the genetic makeup of the $S$. aureus isolate affect biofilm formation ( Lotfi et al.,2014) [21].

In our study we detect biofilm formation genotypically by simple qualitative PCR for detection of ica genes (ica $\mathrm{A}$, ica $\mathrm{B}$, icaC and icaD) as indicator for biofilm formation. PCR is the most widely used technique in molecular biology because it is simple, sensitive, specific and very efficient compared to other methods[22].In the present study, 70 strains $(70 \%)$ were found to contain one or more of these genes and 30 strains (30\%) were negative for all genes. We found that there Ica A was present in $23 \%$ of isolates, Ica B was present in $11 \%$ of isolates, Ica C was present in $9 \%$ of isolates and Ica D was present in $70 \%$ of isolates. (Diemond-Hernández et al.,2010) [10] detect ica A in $10.3 \%$ and ica D in $97.5 \%$ of S.aureus isolates and didn't detect ica B or ica C. Al-Mtory et al. (2016) [22] and Mirzaee et al., (2014) [23] reported higher percentage than our study. Al-Mtory et al. (2016) [22] demonstrate that the prevalence of icaA, icaB , icaC and icaD were $95.8 \%, 91.6 \%, 45.8 \%$ and $95.8 \%$ respectively. In a study of
Mirzaee et al. (2014) [23] ,the prevalence of icaA, icaB, icaC and icaD were $51.6 \%, 45.1 \%, 77.4 \%$ and $80.6 \%$ respectively. Torlak et al., (2017) [24] and Tekeli et al.(2016) [25] reported high prevalence of ica genes among $S$. aureus where all isolates of $S$. aureus were reported to possess ica A and ica D genes. Arciola et al. (2001)[9] and Gad et al. (2009)[12] who detected ica A and ica D genes in all biofilm $S$. aureus isolates. The inconsistency across various studies might be due to heterogeneity in the origins of bacteria such as genetic characterization, source of isolation and environmental conditions.

On comparison between TCP and genotypic method for detection of biofilm formation; sensitivity of TCP in comparison to PCR was $97.1 \%$, specificity was $73.3 \%$, positive predictive value was $89.5 \%$ and negative predictive value was $91.7 \%$. Most studies on biofilm agreed with our study and reported high sensitivity ,specificity, positive predictive value and negative predictive value of TCP Mirzaee et al. (2014) [23] . Aricola et al. (2002)[9] , Gad et al. (2009) [12] and Oliveira and Cunha Maria de Lourdes (2010) [26] .

In our study, two isolates was positive biofilm producer by PCR and negative biofilm producer by TCP this could depend on the culture condition in MTP causing variability depending on the type of incubation medium, so some strains appear negative because their phenotype is not completely expressed in TSB broth. Eight isolates were non biofilm producers by PCR and positive biofilm producers by TCP method. There was high 
statistically significant relation between TCP and PCR methods for detection of biofilm (p value < 0.0001). This is in coordenence with Mirzaee et al. (2014) [23]. also found that one of the S.aureus isolates included in their study was negative for all of ica genes but still produced biofilm as shown by MTP method, suggesting that the difference between the phenotypic and the genotypic characterization of the strain may be explained by an alternative PIAindependent mechanism for biofilm formation in this isolate. On the other hand, inability of biofilm formation in some staphylococcal strains, despite the presence of ica genes can be caused by insertion of a 1332-bp insertion element (IS256), in icaA gene and causing its inactivation [27] . On comparison between congo red and genotypic method for detection of biofilm formation; sensitivity of congo red method was $77.1 \%$, specificity was $33.3 \%$, positive predictive value was $73 \%$ and negative predictive value was $38.5 \%$. Sixteen isolates was positive biofilm producer by PCR and negative biofilm producer by congo red method. Twenty isolates were non biofilm producers by PCR and positive biofilm producers by congo red method .54 isolates were positive biofilm producers of 70 isolates positive by PCR. There was statistically significant relation between CRA and PCR methods for detection of biofilm ( $\boldsymbol{p}$ value $\mathbf{0 . 0 0 8}$ ). Solati et al.(2015) [28], Aricola et al. (2005) [29] and Terki et al. (2013) [30] demonstrated also agreement between results of between CRA and PCR. In our study, positivity at the CRA plate test did not always correlate with the presence of ica A and ica $\mathrm{D}$ genes, in accordance with El-Amin et al.(2015) [31] who demonstrated that $2 \%$ of strains with ica genes did not express phenotype. Liberto et al.(2007) [32] hypothesize a translational or post-translational regulation with production of proteins with low or absent activity, associated with an absent phenotype. As Slime production and association in biofilm are two parameters of great complexity: they are highly correlated with the environment. Indeed, anaerobiosis and low concentrations of iron strongly increase biofilm expression (Baldassarri et al.,(2001) [33] and Cramton et al., (2001) [34] . On the other hand, recent studies highlighted the role of phenol- soluble modulines that can control the passage from biofilm phase to non-biofilm phase, with subsequent dissemination (Yao et al., 2005) [35]. More- over, glucose concentration and, even more, glucose uptake of a particular strain ,and/or a peculiar phase of the growth curve ,can influence ica operon transcription and biofilm expression (Dobinsky et al., 2003) [36].

In contrast to this study Nasr et al.(2012) [13] reported low sensitivity (31.25\%) and specificity (47.05\%) of CRA method in comparison to genotypic method and don't recommended it for detection of biofilm formation by staphylococcal clinical isolates. Oliveira and Cunha Maria de Lourdes, (2010) [26] study showed higher sensitivity (89\%) and specificity $(100 \%)$ of CRA method in comparison to ica genes. However, these authors concluded that CRA might be imprecise in the identification of positive isolates when compared to molecular analysis of the genes involved in biofilm production.

Regarding to studying some the possible risk factors for biofilm formation by S.aureus in infected wounds our study revealed that; The mean age $\pm \mathrm{SD}$ was $35.1 \pm 21.6$ for cases and 37.0 \pm 19.0 for controls with 
$(P$ value $=0.585)$. The median age was 31 years for cases and 40 for controls . The range for age was (470) for cases and (4 - 72) for controls which is statistically insignificant so no relation between age of the patients and biofilm formation by S.aureus in infected wounds. These results are in agreement with Shakibaie et al.(2015) [37] and Cha et al., (2013) [38] who found no relation between age of the patients and biofilm formation( $\boldsymbol{p}$ value $=0.343$ and 0.203 respectively). The sex distribution among cases was 41 males representing $(83.7 \%)$ of all males included in the study and 29 females representing $(56.9 \%)$ of all females included in the study, while the controls was 8 males representing $(16.3 \%)$ of all males included in the study and 22 females representing $(43.1 \%)$ of all females included in the study with (P value 0.003 ) which is statistically significant so there was significant relation between male gender and biofilm formation by S.aureus in infected wounds .This is in agreement with Cha et al. (2013) [38] and Taj et al. (2011) [18] and showed that gender had no relation with biofilm formation ( $p$ value 0.990 and 0.476 respectively).

Regarding to the type of wound of studied population; 60(60\%) S.aureus isolates were from infected surgical wounds, $18(18 \%)$ isolates from infected diabetic foot, 10 (10\%) from infected bed sores ,7(7\%) from infected burn wounds and 5(5\%) from infected chronic wounds. There was a strong relationship between biofilm formation by S.aureus and bed sore infections (P value is <0.05). Abarna et al., (2017) [39] found no relation between type of wound and biofilm formation.

DM impacts the immune system and impair wound healing and impaired perfusion and tissue oxygenation as a result of the microvascular changes associated with DM this leads to higher possibility of infection and biofilm formation[40]. Yet, In our study there was no relation between biofilm formation and DM , the same was found by Luther et al.(2018) [41]. This may be the due to low number of diabetic patients enrolled in our study $(\sim 25 \%)$; thus, limiting the power of the analysis.

In general, implantation of medical devices (e.g., materials for wound stabilization, catheters, and joint prosthetics) has been frequently associated with the production of biofilms and subsequent infections(Arciola et al., 2015) [42] and (Zalipour et al., 2016) [43]. Therefore, it was surprising that the presence of medical hardware was not statistically significant in our study . One explanation could be the low number of wounds that had implantation of medical hardware $(\sim 23 \%)$; thus, limiting the power of the analysis. Results of Luther et al.(2018) [41] and Akers et al.(2014) [44] are similar to our study.

There was highly significant relation between previous hospital admission and biofilm formation Luther et al.(2018) [41] Shakibaie et al. (2014) [37] and Cha et al. (2013) [38] reported the same results while Abarna et al.(2017) [39] found no difference between biofilm forming and nom forming groups.

Using of broad spectrum antibiotics and presence of chronic diseases (other than DM) that affect wound healing -like anaemia ,ischemia and malnutrition - have highly significant relation with biofilm formation by S.aureus in infected wounds ( $p$ value $<0.001)$. Luther et al.(2018) [41] and Abarna et al., (2017) [39] reported no difference between biofilm forming and non biofilm regarding to these comorbidities while groups Taj et al. ( 2011) [18] results 
were the similar to this study. The discrepancy in clinical risk factors affecting biofilm formation may be due to different size and of the samples and difference between in vitro and in vivo biofilm formation and accuracy in recording data of the patients.

\section{Conclusion}

This study illustrated that biofilm formation is an important cause of antibiotic resistance in S.aureus isolated from infected wounds. Our results have confirmed data presented by other authors in that the presence of icaADBC operon genes is associated with biofilm formation .Therefore, both genotypic and phenotypic methods improve identification biofilm ability by S.aureus. PCR method can be adopted as most suitable an reproducible method for detection of biofilm. CRA is qualitative, Simple, inexpensive and easily reproducible method and convenient as screening method. TCP is semiquantitative method and remain a precious tool for in vitro screening of different biomaterial for the adhesive properties .Each method has its advantages and drawbacks, as well as their specific indication. On the other hand, the biofilm-forming ability of some strains in the absence of icaABCD genes highlights the importance of further genetic investigations of ica independent biofilm formation mechanisms.

Regular surveillance of biofilm formation by $S$. aureus and their antimicrobial resistance profile leads to the early treatment of the wound infection.

\section{Reference}

1. Tong, S. Y., Davis, J. S., Eichenberger, E., Holland, T. L., \& Fowler, V. G. (2015). Staphylococcus aureus infections: epidemiology, pathophysiology, clinical manifestations, management. Clinical microbiology reviews, 28(3), 603-661.

2. Neopane, P., Nepal, H. P., Shrestha, R., Uehara, O., \& Abiko, Y. (2018). In vitro biofilm formation by Staphylococcus aureus isolated from wounds of hospital-admitted patients and their association with antimicrobial resistance. International Journal of General Medicine, 11, 25.

3. Taylor, T. A., \& Unakal, C. G. (2017). Staphylococcus Aureus.

4. Anderson, G. G., \& O'toole, G. A. (2008). Innate and induced resistance mechanisms of bacterial biofilms. In Bacterial Biofilms(pp. 85-105). Springer, Berlin, Heidelberg.

5. Hassan, A., Usman, J., Kaleem, F., Omair, M., Khalid, A., \& Iqbal, M. (2011). Evaluation of different detection methods of biofilm formation in the clinical isolates. Brazilian Journal of Infectious Diseases, 15(4), 305-311.

6. Christensen, G. D., Simpson, W. A., Bisno, A. L., \& Beachey, E. H. (1982). Adherence of slime-producing strains of Staphylococcus epidermidis to smooth surfaces. Infection and immunity, 37(1), 318-326.

7. Stepanović, S., Vuković, D., Hola, V., BONAVENTURA, G. D., Djukić, S., Ćirković, I., \& Ruzicka, F. (2007). Quantification of biofilm in microtiter plates: overview of testing conditions and practical recommendations for assessment of biofilm production by staphylococci. Apmis, 115(8), 891899.

8. Zhang, Y. J., Zhang, S., Liu, X. Z., Wen, H. A., \& Wang, M. (2010). A simple method of genomic DNA extraction suitable for analysis of bulk fungal strains. Letters in applied microbiology, 51(1), 114-118.

9. Arciola, C. R., Baldassarri, L., \& Montanaro, L. (2001). Presence of icaA and icaDGenes and slime production in a collection of Staphylococcal strains from catheterassociated infections. Journal of clinical microbiology, 39(6), 21512156.

10. Diemond-Hernández, B., SolórzanoSantos, F., Leaños-Miranda, B., 
Peregrino-Bejarano, L., \& MirandaNovales, G. (2010). Production of icaADBC-encoded polysaccharide intercellular adhesin and therapeutic failure in pediatric patients with staphylococcal infections. BMC device-related diseases, 10(1), 68.

11. Yazdani, R., Oshaghi, M., Havayi, A., Pishva, E., Salehi, R., Sadeghizadeh, M., \& Foroohesh, H. (2006). Detection of icaAD gene and biofilm formation in Staphylococcus aureus isolates from wound infections. Iranian Journal of Public Health, 35(2), 25-28.

12. Gad, G. F. M., El-Feky, M. A., ElRehewy, M. S., Hassan, M. A., Abolella, H., \& El-Baky, R. M. A. (2009). Detection of icaA, icaD genes and biofilm production by Staphylococcus aureus and Staphylococcus epidermidis isolated from urinary tract catheterized patients. The Journal of Infection in Developing Countries, 3(05), 342-351.

13. Nasr, R. A., AbuShady, H. M., \& Hussein, H. S. (2012). Biofilm formation and presence of icaAD gene in clinical isolates of staphylococci. Egyptian journal of medical human genetics, 13(3), 269274.

14. Poudel, P., Poudel, P., Adhikari, N., \& Shah, P. K. (2015). Multi-drug resistant bacterial isolates associated with blood stream infection. American Scientific Research Journal for Engineering, Technology, and Sciences (ASRJETS), 14(2), 23-52.

15. Jesline, A., John, N. P., Narayanan, P. M., Vani, C., \& Murugan, S. (2015). Antimicrobial activity of zinc and titanium dioxide nanoparticles against biofilm-producing methicillin-resistant Staphylococcus aureus. Applied

16. Hurlow, J., Couch, K., Laforet, K., Bolton, L., Metcalf, D., \& Bowler, P. (2015). Clinical biofilms: a challenging frontier in wound care. Advances in wound care, 4(5), 295301.

17. Namvar, A. E., Asghari, B., Ezzatifar, F., Azizi, G., \& Lari, A. R. (2013). Detection of the intercellular adhesion gene cluster (ica) in clinical Staphylococcus aureus isolates. GMS hygiene and infection control, 8(1).

18. Taj, Y., Essa, F., Aziz, F., \& Kazmi, S. U. (2011). Study on biofilmforming properties of clinical isolates of Staphylococcus aureus. The Journal of Infection in Developing Countries, 6(05), 403-409.

19. Mathur, T., Singhal, S., Khan, S., Upadhyay, D. J., Fatma, T., \& Rattan, A. (2006). Detection of biofilm formation among the clinical isolates of staphylococci: an evaluation of three different screening methods. Indian journal of medical microbiology, 24(1), 25.

20. Cafiso, V., Bertuccio, T., Santagati, M., Campanile, F., Amicosante, G., Perilli, M. G., ... \& Stefani, S. (2004). Presence of the ica operon in clinical isolates of Staphylococcus epidermidis and its role in biofilm production. Clinical Microbiology and Infection, 10(12), 1081-1088.

21. Lotfi, G. H. E. L. L. A. I., Hafida, H. A. S. S. A. I. N. E., Nihel, K. L. O. U. C. H. E., Abdelmonaim, K. H. A. D. I. R., Nadia, A. I. S. S. A. O. U. I., Fatima, N. A. S., \& Walter, Z. I. N. G. G. (2014). Detection of biofilm formation of a collection of fifty strains of Staphylococcus aureus isolated in Algeria at the University Hospital of Tlemcen. African Journal of Bacteriology Research, 6(1), 1-6.

22. Al-Mtory, H. K. Y., Al-Shukri, M. S., \& Al-Hassnawi, (2016). H. H. DETECTION OF INTRACELLULAR ADHESION (ica) GENES AND BIOFILM FORMATION IN STAPHYLOCOCCUS SPP. ISOLATED FROM DIFFERENT CLINICAL SAMPLES.

23. Mirzaee, M., Najar Peerayeh, S., \& Ghasemian, A. M. (2014). Detection of icaABCD genes and biofilm formation in clinical isolates of methicillin resistant Staphylococcus aureus. Iranian Journal of Pathology, 9(4), 257-262.

24. Torlak, E., Korkut, E., Uncu, A. T., \& Şener, Y. (2017). Biofilm formation by Staphylococcus aureus isolates 
from a dental clinic in Konya, Turkey. Journal of infection and public health, 10(6), 809-813.

25. Tekeli, A., Ocal, D. N., Ozmen, B. B., Karahan, Z. C., \& Dolapci, I. (2016). Molecular characterization of methicillin-resistant Staphylococcus aureus bloodstream isolates in a Turkish university hospital between 2002 and 2012. Microbial Drug Resistance, 22(7), 564-569.

26. Oliveira, A., \& Maria de Lourdes, R. S. (2010). Comparison of methods for the detection of biofilm production in coagulase-negative

staphylococci. BMC research notes, 3(1), 260.

27. Handke, L. D., Conlon, K. M., Slater, S. R., Elbaruni, S., Fitzpatrick, F., Humphreys, H., ... \& O'gara, J. P. (2004). Genetic and phenotypic analysis of biofilm phenotypic variation in multiple Staphylococcus epidermidis isolates. Journal of medical microbiology, 53(5), 367-374.

28. Solati, S. M., Tajbakhsh, E., Khamesipour, F., \& Gugnani, H. C. (2015). Prevalence of virulence genes of biofilm producing strains of Staphylococcus epidermidis isolated from clinical samples in Iran. $A M B$ Express, 5(1), 47.

29. Arciola, C. R., Campoccia, D., Gamberini, S., Baldassarri, L., \& Montanaro, L. (2005). Prevalence of cna, fnbA and fnbB adhesin genes among Staphylococcus aureus isolates from orthopedic infections associated to different types of implant. FEMS microbiology letters, 246(1), 81-86.

30. Terki, I. K., Hassaine, H., Oufrid, S., Bellifa, S., Mhamedi, I., Lachachi, M., \& Timinouni, M. (2013). Detection of icaA and icaD genes and biofilm formation in Staphylococcus spp. isolated from urinary catheters at the University Hospital of Tlemcen (Algeria). African Journal of Microbiology Research, 7(47), 53505357.

31. El-Amin, M. M., Mohamed, H. E., Abd-Elrazek, G., \& Amer, N. G. (2015). Comparison of different methods for detection of biofilm formation in Staphylococcus aureus and epidermidis isolates from central venous catheters. Int. J. Advan. Res, 3(7), 93-101.

32. Liberto, M. C., Matera, G., Quirino, A., Lamberti, A. G., Capicotto, R., Puccio, R., ... \& Foca, A. (2009). Phenotypic and genotypic evaluation of slime production by conventional and molecular microbiological techniques. Microbiological Research, 164(5), 522-528.

33. Baldassarri, L., Bertuccini, L., Ammendolia, M. G., Arciola, C. R., \& Montanaro, L. (2001). Effect of iron limitation on slime production by Staphylococcus aureus. European Journal of Clinical Microbiology and Infectious Diseases, 20(5), 343-345.

34. Cramton, S. E., Ulrich, M., Götz, F., \& Döring, G. (2001). Anaerobic conditions induce expression of polysaccharide intercellular adhesin in Staphylococcus aureus and Staphylococcus epidermidis. Infection and immunity, 69(6), 4079-4085.

35. Yao, Y., Sturdevant, D. E., \& Otto, M. (2005). Genomewide analysis of gene expression in Staphylococcus epidermidis biofilms: insights into the pathophysiology of $S$. epidermidis biofilms and the role of phenol-soluble modulins in formation of biofilms. Journal of Infectious Diseases, 191(2), 289-298.

36. Dobinsky, S., Kiel, K., Rohde, H., Bartscht, K., Knobloch, J. K. M., Horstkotte, M. A., \& Mack, D. (2003). Glucose-related dissociation between icaADBC transcription and biofilm expression by Staphylococcus epidermidis: evidence for an additional factor required for polysaccharide intercellular adhesin synthesis. Journal of bacteriology, 185(9), 2879-2886.

37. Golkari, Y., \& Salagegheh, G. (2014). Antimicrobial susceptibility, virulence factors and biofilm formation among Staphylococcus aureus strains from hospital infections in Kerman, Iran. Journal of Microbiology and Infectious Diseases, 4(04).

38. Cha, J. O., Yoo, J. I., Yoo, J. S., Chung, H. S., Park, S. H., Kim, H. S., ... \& Chung, G. T. (2013). 
Investigation of biofilm formation and its association with the molecular and clinical characteristics of methicillinresistant Staphylococcus aureus. Osong public health and research perspectives, 4(5), 225-232.

39. Abarna, V. Sri Sakthipriya , N. Anitha Raj , M. Arthi, E \& Bagyalakshmi, R.(2017). Detection of Biofilm production in microorganisms complicating Chronic wound infections. Tropical Journal of Pathology \& Microbiology, 362, 1 - 5

40. Guo, S. A., \& DiPietro, L. A. (2010). Factors affecting wound healing. Journal of dental research, 89(3), 219-229.

41. Luther, M. K., Parente, D. M., Caffrey, A. R., Daffinee, K., Lopes, V. V., Martin, E. T., \& LaPlante, K. L. (2018). Clinical and genetic risk factors for biofilm-forming Staphylococcus aureus. Antimicrobial agents and chemotherapy, AAC02252
42. Arciola, C. R., Campoccia, D., Ravaioli, S., \& Montanaro, L. (2015). Polysaccharide intercellular adhesin in biofilm: structural and regulatory aspects. Frontiers in cellular and infection microbiology, 5, 7 .

43. Zalipour, M., Ebrahim-Saraie, H. S., Sarvari, J., \& Khashei, R. (2016). Detection of Biofilm Production Capability and icaA/D Genes Among Staphylococci Isolates from Shiraz, Iran. Jundishapur Journal of Microbiology, 9(12).

44. Akers, K. S., Mende, K., Cheatle, K. A., Zera, W. C., Yu, X., Beckius, M. L., .. \& Weintrob, A. C. (2014). Biofilms and persistent wound infections in United States military trauma patients: a case-control analysis. BMC infectious diseases, 14(1), 190. 
